\title{
Leg length inequality and its relationship with injuries incidence of young basketball players: an observational study.
}

\author{
Lucas Villalta Santos'1, Mateus Francisco Rossi', Claudia Santos Oliveira², Hugo Pasin Neto',2
}

\begin{abstract}
Introduction: The leg length inequality (LLI) creates postural changes collaborating with the emergence of functional limitations and musculoskeletal disorders. In a sport like basketball inequality of the lower limbs may be added to the demands of the sport and generate an increase in the incidence of injuries. Objective: The aim of this study was to identify young basketball players from with structural or functional LLI and its influence in injury incidence in a period of 6 months. Methods: 18 players were followed with an average age of $14.50 \pm 1.86$ of a basketball team from the city of Sorocaba for a period of 6 months. At the beginning and end of that period were applied tests from the Morbidity Survey Report modified for basketball to obtain data such as physical characteristics, training time, incidence of injuries, quantitative and qualitative measurement of the length of the lower limbs. Results: $72.2 \%$ of players had LLI and $50 \%$ had some kind of injury during this period, among the most common, sprains and muscle strains. Conclusions: There was a high rate of players with LLI and a positive relationship between this inequality with the incidence of injury.
\end{abstract}

Key words: Basketball; Athletic Injuries; Leg Length Inequalities.

\section{INTRODUCTION}

One of the most common biomechanical abnormalities in the population is lower limbs inequality (LLI), popularly known as short leg. There are two types of LLI, structural and functional. The structural is related to inequality of bone structures, and functional is related to stiffness or muscle weakness and/or mobility of joints of the pelvis and lower limb, for example, sacroiliac dysfunction (SID), which corresponds to a reversible decrease in joint mobility, without any type of bone displacement. ${ }^{(1)}$

Our body creates compensatory mechanisms, because the LLI changes the position of the center of gravity and the center of pressure. ${ }^{(2)}$ These compensatory mechanisms are: pronation of the foot, hip extension and knee on the long leg; supination of the foot, hip flexion and knee at the short leg ${ }^{(3,4)}$; pelvic obliquity in the frontal plane ${ }^{(4-9)}$; and functional scoliosis of the spine. ${ }^{(5,7,8)}$ These changes make the joints less able to absorb impacts and the muscles more fatigued due to the necessity to balance the body.

All these factors contribute to functional limitations and musculoskeletal disorders to occur. Among the functional limitations are changes in the gait pattern, running and balance ${ }^{(1,10-13)}$; and the musculoskeletal disorders are the low back pain ${ }^{(1,5,8,9,14-16)}$, osteoarthritis of the knee and/or hip ${ }^{(1,13,17,18)}$, and stress fracture. ${ }^{(1,17)}$

Brunet et al. ${ }^{(19)}$ found that LLI is a contributing factor to the development of injuries in activities that involves running, because of the overload generated in the lower limbs. So in a sport like basketball, which involves running with large impacts, intense and short efforts with sudden changes of direction, frequent jumps, landings and pivoting, LLI could be added to the demands of the sport and generate an increase in the incidence of injuries. ${ }^{(3,20,21)}$

Specifically, the inequality of the lower limbs can lead to overuse injuries in basketball players, as it was discovered by Leppänen, Pasanen, and Kujala ${ }^{(22)}$, and the most affected locations were in the lower limbs (knee and pelvis) and the lumbar spine. This type of injury usually affects the practice of sport and the player's ability to compete for a long time.

Thus, the aim of this study was to identify the incidence of inequality of the lower limbs in basketball players and discuss its relation to the injuries presented by them for a period of 6 months. 


\section{METHODS}

This is an observational and cross-sectional study of basketball players aged 10 to 18 years.

\section{Ethical aspects}

The study was approved by the Research Ethics Committee of the University of Sorocaba (UNISO) by the protocol 1.020.268. The study included minors subjects, where the legal guardians had to sign the Informed Consent Form to allow the participation of the minor in the study.

\section{Participants}

To determine the sample, the eligibility criteria was divided into inclusion and exclusion criteria. The inclusion criteria were: being a player belonging to the team Sorocaba Basketball League and aged between 10 and 18 years. On the other hand, the exclusion criteria were: being away from training in the early period of the study and have musculoskeletal pathology that could influence the outcome of the physical test.

\section{Evaluation Tools}

The tools used to evaluate basketball players were a two meters tape measure, a digital scale, a fixed height gauge and a stretcher.

\section{Data Collection}

Data collection was carried out individually by a Morbidity Survey Report (MSR) from Vanderlei et al. ${ }^{(23)}$ and Pastre et al. ${ }^{(24)}$ (Appendix 1). The first phase was the collection of information such as gender, age, body mass, height, body mass index (BMI), months of training, training hours per week, training sessions per week, and previous injuries. Moreover, in this phase were made two leg length assessments to differentiate structural or functional inequalities. The first evaluation quantifies the LLI and was performed using the Tape Measure Method (TMM) based on Neelly et al. ${ }^{(25)}$ study. The second assessment was carried out through the Downing test that seeks to assess the presence of a dysfunction on the pelvis. ${ }^{(26-29)}$

The second phase was carried out over the next 6 months and it is related to the incidence and characteristics of injuries presented during this period. The definition of injury in sport chosen for this study was "any problems that occur in the musculoskeletal system that is originated in sports depriving the player of any activity during training or competition". ${ }^{23,24)}$

The MSR variables follow the same order as Pastre et al. ${ }^{(24)}$ and Vanderlei et al. ${ }^{(23)}$ presented, where the participants were asked 12 different types of injuries (muscle strain, contracture, tendinopathy, etc.), 4 types of injury mechanism (direct contact, a single traumatic event such as an impact of players, without contact, sport activities like jumping and running, and overuse, repetitive microtraumas in the musculoskeletal system without adequate recovery), 19 anatomical sites of injury or discomfort (trunk, shoulder, wrist, hand, thigh, leg, ankle, foot, etc.), 2 types of return to normal activities (asymptomatic and symptomatic), and 2 moments of injury (training or competition).

\section{Statistical analyses}

To interpret the results the Microsoft Excel (2013) was utilized. In addition, it was used an exploratory and descriptive analysis based on the mean and standard deviation (SD) for continuous variables and frequencies and percentages for categorical variables.

\section{RESULTS}

The initial sample counted with the participation of 70 players which after undergoing the eligibility criteria were selected and reduced to 54 . Among these volunteers and players initially selected, 36 were excluded from the sample for reasons such as change of team or sport leave (Figure 1). Thus, the final sample consisted of 18 players whose which the general characteristics are described in Table 1.

Regarding the analysis of the incidence of $\mathrm{LLI}$, considering only the equal or greater differences than $0.5 \mathrm{~cm}$, were found in $72.2 \%$ of the players, of these, $46.1 \%$ had a shorter right leg while $53.9 \%$ presented the same condition in their left leg.

Another result was observed for the presence or absence of dysfunction of the pelvis (SID) associated with LLI. Among the LLI cases, $50 \%$ of them were related to SID, showing a structural change accompanied by a functional one, while in $22.2 \%$ of cases the LLI happened isolated (structural change), and $11.1 \%$ of cases were observed only SID (functional limitation) (Figure 2).

With regard to the incidence of injuries, $50 \%$ of the players reported at least one injury, of these, $66.6 \%$ with LLI associated with SID; $22.2 \%$ with only LLI; and $11.1 \%$ with only SID. Players who did not have LLI or SID did not report any injury. The most common types of injuries were sprains (55.5\%) and muscle strain (44.4\%), and the mechanisms of injury were during running or landing without contact with another player (55.5\%), direct contact with another player (22.2\%) and (22.2\%) overload training. As for the most affected regions: ankle (33.3\%), knee (22.2\%), anterior thigh (22.2\%), hip (11.1\%) and hand (11.1\%).

\section{DISCUSSION}

The results of this study showed a high incidence of $L L I$ in the evaluated players, as well as the high rate of injuries in this group, showing a direct relationship between LLI and the injury rate. This fact can be seen when observed that $88.8 \%$ of the athletes who had injury during the study period had this difference (66.6\% LLI and SID associated; only $22.2 \%$ LLI). Another important aspect observed was that only $22.2 \%$ of injuries were reported by the athletes as due to direct contact with another player demonstrating that the injuries can have 


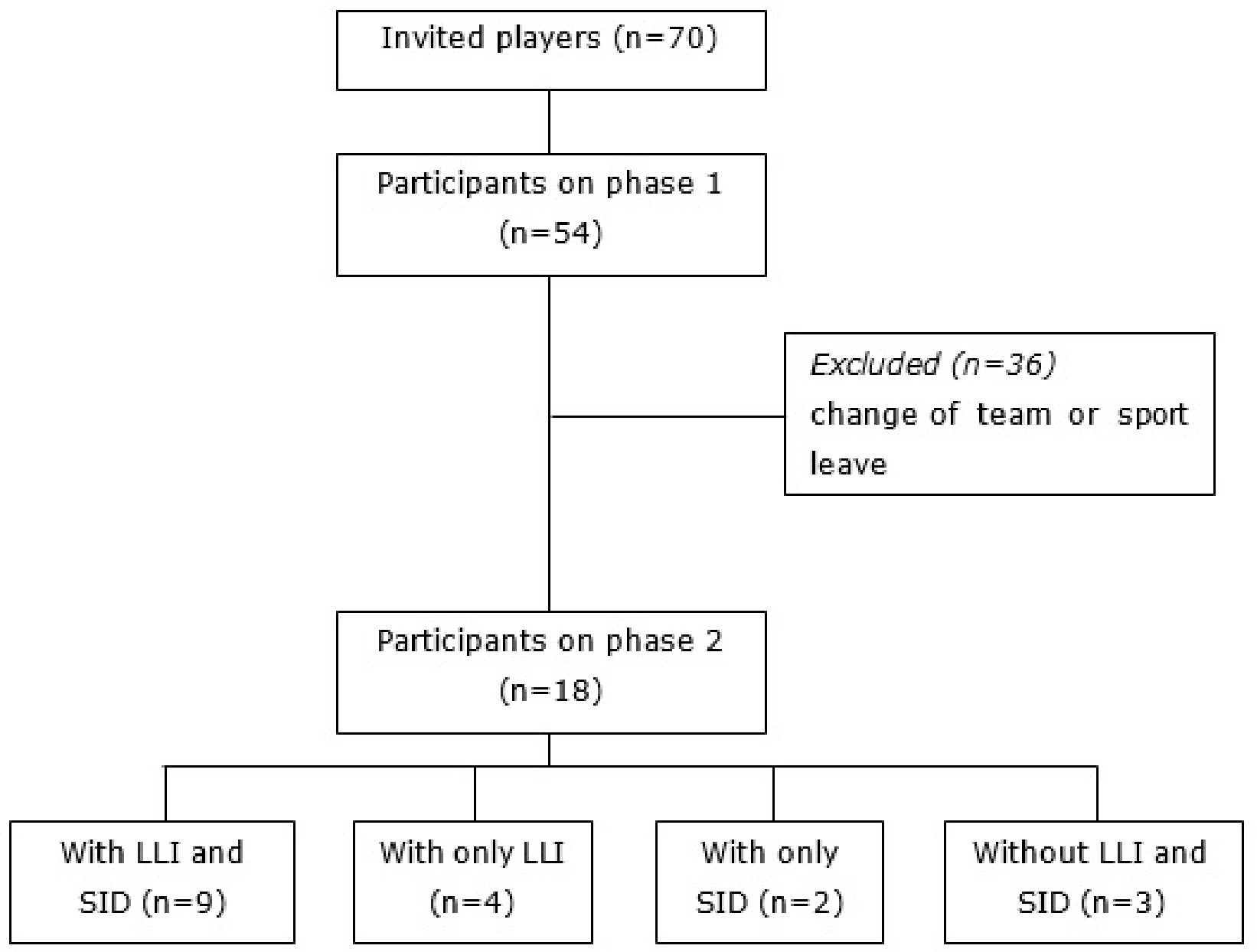

Figure 1 - Flowchart composition of participants

Table 1 - General characteristics of the basketball players

\begin{tabular}{lc}
\hline & Players $(\mathbf{n}=\mathbf{1 8})$ \\
\hline Age (years) & $14.50 \pm 1.86$ \\
Body mass $(\mathrm{kg})$ & $64.07 \pm 13.24$ \\
Height $(\mathrm{m})$ & $1.73 \pm 0.12$ \\
BMI $\left(\mathrm{kg} / \mathrm{m}^{2}\right)$ & $21.19 \pm 2.72$ \\
Months of training & $17.17 \pm 15.70$ \\
Training hours per week & $4.17 \pm 2.03$ \\
Training sessions per week & $2.78 \pm 1.36$ \\
\hline
\end{tabular}

$\mathrm{n}$-number of subjects, $\mathrm{kg}$ - kilogram, $\mathrm{m}$ - meter, BMI-Body Mass Index, $\mathrm{kg} / \mathrm{m}^{2}=$ kilogram per meter squared.

an important functional relationship, and yet the vast majority of them (88.8\%) located in the lower limbs, even in sport that is highly related to the upper limbs.

Other studies showed the relationship of LLI and injuries, such as Brunet et al. ${ }^{19}$ reporting that the biomechanical imbalance generated by LLI in recreational runners can increase from two to four times the body weight, making the body more vulnerable to injury. Liu et al. ${ }^{(30)}$ suggests that individuals with LLI had an increase in the degree of supination of the subtalar joint, producing a stiffer foot thus less capable of absorbing impact, which is more prone to injury. These reports corroborate with the findings of this study, where most players with LLI and SID were injured, mostly in the lower limbs without being by direct contact with other players, indicating that a functional change influence on the incidence and type of injury.

The correction of LLI is defended by authors such as Brunet et al. ${ }^{19}$ to prevent the installation of overuse injuries because it generates postural imbalances that contribute to the occurrence of injuries in running activities. In a functional LLI, that occurs when LLI and SID are associated, the treatment may include temporary postural insoles, joint mobilizations, stretching and strengthening the muscles that generated the DSI. In contrast, the treatment of structural LLI would be performed with the use of permanent postural insoles and postural reeducation. 


\section{7}

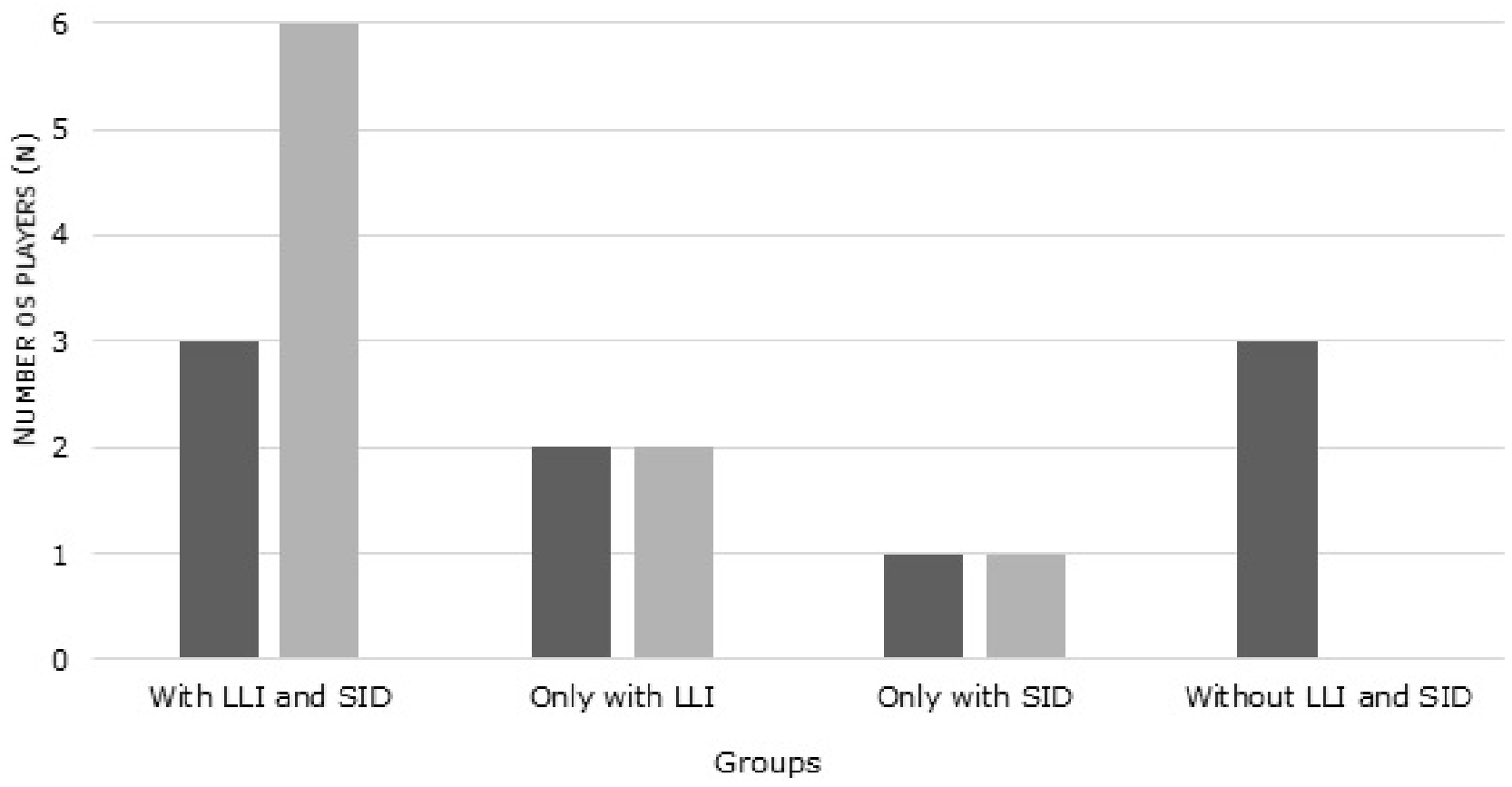

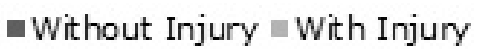

Figure $\mathbf{2}$ - Injury incidence according to the players dysfunction group

With regards to the amount of LLI, in millimeters, needed to prevent or treat potential problems in the musculoskeletal system resulting from this dysfunction, there is no consensus in the literature with a minimal difference to start a treatment. ${ }^{5-7}$ However, considering the functional demand of a high-level sport and the results of this study, it can be justified the need to treat it independently of its size difference.

\section{CONCLUSIONS}

There was a high rate of players with LLI and a positive relationship between this inequality with the incidence and characteristics of injuries, indicating the need to intervene in this inequality, preventively.

\section{ABBREVIATIONS}

LLI - lower limb inequality, SID - sacroiliac dysfunction, $\mathrm{n}$ - number of subjects, $\mathrm{kg}$ - kilogram, $\mathrm{m}$ - meter, BMI - Body Mass Index, $\mathrm{kg} / \mathrm{m}^{2}=$ kilogram per meter squared.

\section{ACKOWLEDGMENTS}

We thank the Medical Department and the Administrative Department of the Sorocaba Basketball League who allowed and supported the data collection of their athletes.

\section{AUTHORS' CONTRIBUTIONS}

LVS carried out the lower limb inequality and incidence of injuries in basketball studies, participated in the data collection, and drafted the manuscript. MFR carried out the biomechanics of injuries in basketball studies and participated in the data collection. CSO coordinated and helped to draft the manuscript. HPN carried out the lower limb inequality studies, performed the statistical analysis and helped to draft the manuscript.

\section{CONFLITS OF INTEREST:}

No.

\section{REFERENCES}

1. Gurney B. Leg length discrepancy. Gait \& Posture [Internet]. 2002;15(2):195-206. Available from: http://www.sciencedirect.com/ science/article/pii/S0966636201001485

2. Betsch M, Schneppendahl J. Influence of foot positions on the spine and pelvis. Arthritis care \& ... [Internet]. 2011 Dec [cited 2014 Aug 29];63(12):1758-65. Available from: http://www.ncbi.nlm.nih.gov/ pubmed/22127967

3. Pereira C, Sacco I. Is structural and mild leg length discrepancy enough to cause a kinetic change in runners' gait? Acta Ortopédica Brasileira [Internet]. 2008 [cited 2014 Oct 24];16:28-31. Available from: http:// www.scielo.br/scielo.php?pid=S1413-78522008000100005\&script=sci_ arttext

4. Walsh $\mathrm{M}$, Connolly $\mathrm{P}$, Jenkinson a, O'Brien T. Leg length discrepancy--an experimental study of compensatory changes in three dimensions using gait analysis. Gait \& posture [Internet]. 2000 Oct;12(2):156-61. Available from: http://www.ncbi.nlm.nih.gov/pubmed/10998613 
5. Raczkowski JW, Daniszewska B, Zolynski K. Functional scoliosis caused by leg length discrepancy. Archives of medical science : AMS [Internet]. 2010 Jun 30 [cited 2014 Aug 29];6(3):393-8. Available from: http://www. pubmedcentral.nih.gov/articlerender.fcgi?artid=3282518\&tool=pmcent rez\&rendertype $=$ abstract

6. Vink $\mathrm{P}$, Kamphuisen $\mathrm{H}$ a. Leg length inequality, pelvic tilt and lumbar back muscle activity during standing. Clinical biomechanics (Bristol, Avon) [Internet]. 1989 May;4(2):115-7. Available from: http://www.ncbi.nlm. nih.gov/pubmed/23916004

7. Betsch $M$, Wild $M$, Große B, Rapp W, Horstmann T. The effect of simulating leg length inequality on spinal posture and pelvic position: a dynamic rasterstereographic analysis. European spine journal : official publication of the European Spine Society, the European Spinal Deformity Society, and the European Section of the Cervical Spine Research Society [Internet]. 2012 Apr [cited 2014 Aug 28];21(4):691-7. Available from: http://www. pubmedcentral.nih.gov/articlerender.fcgi?artid=3326121\&tool=pmcent rez\&rendertype=abstract

8. Defrin R, Benyamin S Ben, Aldubi RD, Pick CG. Conservative correction of leg-length discrepancies of $10 \mathrm{~mm}$ or less for the relief of chronic low back pain. Archives of Physical Medicine and Rehabilitation. 2005;86(11):207580.

9. Kendall J, Bird A, Azari M. Foot posture, leg length discrepancy and low back pain-Their relationship and clinical management using foot orthoses-An overview. The Foot [Internet]. Churchill Livingstone; 2014 [cited 2014 Aug 23];24(2):75-80. Available from: http://www. sciencedirect.com/science/article/pii/S0958259214000121

10. Pereira CS, Sacco IDCN. Desigualdade estrutural discreta de membros inferiores é suficiente para causar alteração cinética na marcha de corredores? Acta Ortopédica Brasileira. 2008;16(1):28-31.

11. Merker A, Rummel J, Seyfarth A. Stable walking with asymmetric legs. Bioinspiration \& biomimetics [Internet]. 2011 Dec [cited 2014 Aug 29];6(4):45004. Available from: http://www.ncbi.nlm.nih.gov/ pubmed/22126858

12. Cole WG, Gill S V, Vereijken B, Adolph KE. Coping with asymmetry: how infants and adults walk with one elongated leg. Infant behavior \& development [Internet]. Elsevier Inc.; 2014 Aug [cited 2014 Aug 24];37(3):305-14. Available from: http://www.ncbi.nlm.nih.gov/ pubmed/24857934

13. Golightly YM, Allen KD, Renner JB, Helmick CG, Salazar a., Jordan JM. Relationship of limb length inequality with radiographic knee and hip osteoarthritis. Osteoarthritis and Cartilage. 2007;15(7):824-9.

14. Burke W. Leg length inequality in humans: A new neurophysiological approach. Neuroscience Letters. 2004;361(1-3):29-31.

15. Rothenberg RJ. Rheumatic Disease Aspects of Leg Length Inequality. Seminars in Arthritis and Theumatism. 1988;17(3):196-205.

16. Rannisto $S$, Okuloff $A$, Uitti J, Paananen $M$, Rannisto $P-H$, Malmivaara A, et al. Leg-length discrepancy is associated with low back pain among those who must stand while working. BMC Musculoskeletal Disorders [Internet]. ???; 2015;16(1):1-7. Available from: http://www. biomedcentral.com/1471-2474/16/110
17. Swaminathan V, Cartwright-Terry M, Moorehead JD, Bowey a., Scott SJ. The effect of leg length discrepancy upon load distribution in the static phase (standing). Gait \& Posture [Internet]. Elsevier B.V.; 2014;40(4):561-3. Available from: http://linkinghub.elsevier.com/ retrieve/pii/S0966636214006407

18. Noll D. Leg Length Discrepancy and Osteoarthritic Knee Pain in the Elderly: An Observational Study. The Journal of the American Osteopathic Association [Internet]. 2013;113(9):670-8. Available from: http://jaoa. org/article.aspx?doi=10.7556/jaoa.2013.033

19. Brunet ME, Cook SD, Brinker MR, Dickinson JA. A survey of running injuries in 1505 competitive and recreational runners. The Journal of sports medicine and physical fitness. ITALY; 1990 Sep;30(3):307-15.

20. Moreira P, Gentil D, de Oliveira C. Prevalência de lesões das equipes de base e adultas que representaram a Seleção Brasileira de Basquete em 2003. Revista Brasileira de Medicina do Esporte. 2006;14:258-66.

21. Acquesta FM, Peneireiro GM, Bianco R, Amadio AC, Serrão JC. Características dinâmicas de movimentos seleccionados do basquetebol. Revista Portuguesa de Ciências do Desporto [Internet]. Faculdade de Desporto da Universidade do Porto; 2007 [cited 2016 Jan 14];7(2):17482. Available from: http://www.scielo.mec.pt/scielo.php?script=sci_ arttext\&pid=S1645-05232007000200005\&lng=pt\&nrm=iso\&tlng=pt

22. Leppänen $M$, Pasanen $K$, Kujala UM. Overuse injuries in youth basketball and floorball. 2015;173-9.

23. Vanderlei FM, Bastos FN, Tsutsumi GYC, Vanderlei LCM, Netto Júnior J, Pastre CM. Characteristics and contributing factors related to sports injuries in young volleyball players. BMC research notes [Internet]. 2013 Jan [cited 2014 Aug 30];6:415. Available from: http://www. pubmedcentral.nih.gov/articlerender.fcgi?artid $=4015734 \&$ tool=pmcen trez\&rendertype=abstract

24. Pastre CM, Carvalho Filho G, Monteiro HL, Netto Júnior J, Padovani CR. Lesões desportivas no atletismo: comparação entre informações obtidas em prontuários e inquéritos de morbidade referida. Revista Brasileira de Medicina do Esporte. 2004;10:1-8.

25. Neelly K, Wallmann HW, Backus $\mathrm{CJ}$. Validity of measuring leg length with a tape measure compared to a computed tomography scan. Physiotherapy theory and practice [Internet]. 2013 Aug [cited 2014 Aug 29];29(6):48792. Available from: http://www.ncbi.nlm.nih.gov/pubmed/23289961

26. Walker JM. The sacroiliac joint: a critical review. Physical therapy. 1992;72(12):903-16.

27. van der Wurff $P$, Meyne $W$, Hagmeijer RH. Clinical tests of the sacroiliac joint. Manual therapy. 2000;5(2):89-96.

28. Oliveira RS de, Bigolin SE. Avaliação do posicionamento dos ilíacos em sujeitos que trabalham sentados e a relação com a dor lombar. Universidade Regional do Noroeste do Estado do Rio Grande do Sul; 2011.

29. Piazza L, Luza M. Disfunção sacro-ilíaca: uma revisão de literatura. EFDeportes.com Revista Digital. 2011;16(156):5-9.

30. Liu X-C, Fabry G, Molenaers G, Lammens J, Moens P. Kinematic and Kinetic Asymmetry in Patients with Leg-Length Discrepancy. Journal of Pediatric Orthopaedics [Internet]. 1998;18(2). Available from: http://journals.Iww. com/pedorthopaedics/Fulltext/1998/03000/Kinematic_and_Kinetic_ Asymmetry_in_Patients_with.10.aspx 
Appendix 1: Morbidity Survey Report - Basketball

ID: Age:

Months of training:

Previous injuries
Height: Training hours/week:
BMI:

Training sessions/week:

\begin{tabular}{|l|l|l|l|}
\hline \multicolumn{1}{|c|}{ Lower limbs } & Size $(\mathrm{mm})$ & Anterior iliac mobility & Posterior iliac mobility \\
\hline Right & & & \\
\hline Left & & & \\
\hline
\end{tabular}

\begin{tabular}{|c|c|c|c|c|c|c|c|c|}
\hline Variables & \multicolumn{8}{|c|}{ Sport injuries } \\
\hline ID of sport injury & $1 \underline{a}$ & $2^{\mathrm{a}}$ & $3^{3} \mathfrak{a}$ & $4^{\mathrm{a}}$ & $5 \underline{a}$ & $6 \underline{a}$ & $7 \underline{a}$ & $8 \underline{a}$ \\
\hline Type of injury & & & & & & & & \\
\hline Mechanicsm of inju & & & & & & & & \\
\hline Anatomical sites & & & & & & & & \\
\hline $\begin{array}{l}\text { Return to normal } \\
\text { acitivities }\end{array}$ & & & & & & & & \\
\hline Moments of injury & & & & & & & & \\
\hline
\end{tabular}

\section{Codification of variables}

\begin{tabular}{|c|c|c|c|}
\hline Type of injury & Mechanism of injury & \multicolumn{2}{|c|}{ Anatomical sites } \\
\hline 1- Mescle strain & 1- Direct contact & 1-Shoulder & 13-Posterior thigh \\
\hline 2- Muscle contracture & 2- Without contact & 2-Arm & 14- Knee \\
\hline 3-Tendionopathy & 3-Overuse & 3-Forearm & 15- Leg \\
\hline 4- Sprain & 4- Other & 4- Elbow & 16- Calf \\
\hline 5- Muscle pain & & 5- Wrist & 17-Ankle \\
\hline 6- Periostitis & & 6- Hand & 18-Foot \\
\hline 7- Synovitis & & 7- Thorax & 19- Other \\
\hline 8- Fracture & & 8-Abdomen & \\
\hline 9- Bursitis & & 9- Lumbar region & \\
\hline 10- Inespecific acute pain & & 10- Cervical region & \\
\hline 11- Inespecific chronic pain & & 11- Нip & \\
\hline 12- Other & & 12- Anterior thigh & \\
\hline
\end{tabular}

\begin{tabular}{|l|}
\hline \multicolumn{1}{|c|}{ Return to normal activities } \\
\hline 1- Asymptomatic \\
\hline 2- Symptomatic \\
\hline
\end{tabular}

\begin{tabular}{|c|}
\hline Moment of injury \\
\hline 1- Training \\
\hline 2- Competition \\
\hline
\end{tabular}

